\title{
The signaling effect of group-type profile pictures in the sharing economy: The case of Airbnb
}

\author{
Donggyu Min \\ KAIST \\ donggyu.min@kaist.ac.kr
}

\author{
Chulho Lee \\ KAIST \\ irontigerlee@kaist.ac.kr
}

\author{
Yasin Ceran \\ KAIST \\ $\underline{\text { yceran@kaist.ac.kr }}$
}

\author{
Tom Steinberger \\ KAIST \\ tomsteinberger@kaist.ac.kr
}

\begin{abstract}
While Airbnb hosts may publish various details of their property on the online platform to persuade travelers to make bookings, they choose to post limited information about themselves, except their profile pictures. Based on the signaling and uncertainty reduction theories, we focus on the impact of host profile pictures on bookings and hypothesize that (1) the presence of a profile picture induces the travelers to trust the host more, (2) the number of people in a picture, a proxy for sociality in trustworthiness, increases bookings, and (3) these two impacts are intensified for properties in risky neighborhoods. Collecting profile pictures of 14,799 hosts on Airbnb, we utilized a deep learning-based face detection technique to extract the number of different faces in a profile and ran random effects models to test our hypotheses. This study is unique in its using archival data to show the impact of profile pictures on bookings.
\end{abstract}

\section{Introduction}

Recently, sharing economy, a new type of online peer-to-peer ( $\mathrm{p} 2 \mathrm{p})$ market that is mainly represented by Uber or Airbnb, has grown rapidly. In sharing economy platforms, sellers generate profits by sharing their assets [1]. In many cases, the seller and buyer interact with each other on an online platform, and, unlike the offline marketplace where people can access the product quality by "kicking the tires", consumers have difficulty in estimating the quality of the product prior to the transaction [2]. Due to information asymmetry, the innate characteristics of online markets, consumers face the risk of adverse selection and moral hazard [3, 4]. Moreover, as sharing economy presupposes actual encounter between sellers and buyers, a transaction may occasionally put the buyer in a risky, and sometimes dangerous, situation. According to Airbnb, $0.05 \%$ of guests generates safety-related reports, which is roughly 1000 cases per day [5]. Uber also revealed that 3,045 sexual assaults were committed during 2018 [6].
As the consumers interact with total strangers through a software platform without any prior knowledge, they rely on the trustworthiness of sellers. However, online platform do not provide sufficient cues for buyers to assess the trustworthiness of a seller. Given the shortage of reliable information about the seller, a profile picture may take a crucial role in building the perceived trustworthiness of the seller. Thus, a potential relationship between profile pictures and sales received attention among researchers. Although some of the studies showed that profile pictures have significant impact on sales [7, 8, 9, 10], this effect was not empirically explored using archival data. To fill this gap in the literature, employing archival data in this study, we aimed to identify the effect of posting profile pictures on the sales at a software platform.

When exploring the link between the profile pictures and sales, we took one step further and focused on group profile pictures. Hypothesizing that group profile pictures might be perceived as a sign of sociability and thus perceived trustworthiness, we also investigated the effect of having group profile photo on consumers decision making. To the best of our knowledge, this study is the first one considering the relationship between the perceived sociability, trustworthiness, and sales.

To create the archival data, we collected profile pictures of 14,799 hosts on Airbnb and extracted the number of faces in the profile picture employing DSFD (Dual Shot Face Detector), which is a deep learningbased face detection model. We analyzed the effect of profile pictures on Airbnb's accommodation reservation rate with random effects model. Through this, we confirmed that profile photos in the form of group photos act as a positive sign for consumers.

In addition, consistent with the trust-intensive nature of sharing economy in accommodation, we assumed that the impact of having profile picture or group profile picture is intensified for properties located at risky neighborhoods. To test the validity of our assumption, we examined the moderation effect of crime rate on the relationship between profile picture and sales. Our study 
provides practical guidelines to platform owners and merchandisers by identifying factors to facilitate consumer purchases.

The remainder of this paper is organized as follows. In section 2, we describe the literature regarding trustworthiness, signaling effect and the impact of profile photo. Next, in section 3, we explain the conceptual framework. In section 4, we clarify our data collection process and method and describe the specific variables. Then, in sections 5 and 6 , we present our main results along with a set of robustness checks. Finally, in section 7, we conclude the paper with a discussion on limitations and implications of this paper.

\section{Literature Review}

In the following, we explore two streams of literature related to our study. First, we review the research on perceived trustworthiness, perceived sociability, and profile pictures. Next, we provide an overview of relevant literature on signaling theory.

\subsection{Perceived trustworthiness and profile pictures}

Perceived trustworthiness is defined as the perceived goodness or morality of the source [11]. As the consumers interact with total strangers through a software platform without any prior knowledge, they rely on the trustworthiness of sellers. Oliver and Anja [12] demonstrated that trustworthiness promotes both intention to buy and actual behavior in online markets.

In online environment where sellers do not receive satisfactory information about the buyers, prior research investigated the impact of sellers' profile pictures on the buyers. These studies focus on three aspects of the profile pictures: trustworthiness, attractiveness, and facial expression. First, borrowers with trustworthy looking profile pictures are shown to secure more money in $\mathrm{p} 2 \mathrm{p}$ lending platforms [10]. In another study, it was found that Airbnb hosts with trustworthy face get more visitors [7]. Second, Peng et al. [13] found that beauty and ugliness based on profile photos in e-commerce platforms is effective on the sales, in particular, that the facial attractiveness of hosts in Airbnb have positive effect on occupancy rates. Finally, the impact of facial expressions in the profile pictures, such as making an eye contact [14] or smiling [15], are found to be making a positive impact on the number of Airbnb bookings. However, these studies did not employ archival data and mainly relied on surveys. Different from the prior literature, we explore the impact of profile pictures based on a large archival dataset.

\subsection{Perceived sociability and group profile pictures}

As trustworthiness and credibility are shown to have a positive effect on the transactions of two stakeholders, the sociability that constitutes these two constructs has also received much attention from researchers [16. [17, 18]. Banerjee [19] empirically proved that perceived sociability through number of friends in profile pictures has a positive impact on the perceived trustworthiness of online reviewers.

In an online environment where both verbal and non-verbal communication are limited compared to a face-to-face setting, any given social information can be instrumental in evaluating people interacting online [20]. Social information can be captured from comments [21, 22, 23], likes [22], or number of friends [22. 24]. In addition to these social cues, some researchers estimated sociability through profile pictures [23, 25, 26]. For instance, Hong [23] defined every element that can give personal or social information in profile photos as a social cue (e.g. violin or a school jersey), and has shown that these social cues have a positive impact on social attractiveness and popularity.

Although number of friends in social media is used as a metric for sociability, little is known about perceived sociability from friend information in profile photos. As group photos contain more social cues as to whether an individual is extroversion and has relationships with others, one might easily infer the sociability from group photos than individual photos. To the best of our knowledge, research on the effectiveness of group profile photo has not demonstrated significant impact on measuring sociability [25], or limited to specific relationship [26]. To fill the research gap, we conducted the analysis using large amounts of archival data, where $34 \%$ of profiles are group photos.

\subsection{Signaling theory}

Signaling theory provides a framework to explain the behavior of reducing information asymmetry between two parties [27]. The signaling theory was initially developed by Michael Spence [28] by observing knowledge gaps between organizations and prospective employees. Even though this concept was first introduced in the context of job market, signaling theory holds a prominent position in a variety of applications in the literature [27]. For example, signaling effect for a supplier with sufficient information is to provide information about the quality of their own products to the consumer in the presence of an information asymmetry.

Especially in relationship between consumer and buyer, signaling plays a crucial role to promote purchas- 
ing behavior by influencing consumer perceptions [29]. Moreover, with the emergence of online platforms that has significant levels of information asymmetry, there has been a growing body of research that explores signaling effect in online markets. For example, signaling theory has been used to determine success factors in various forms of online services, such as crowdfunding [30, 31], online commerce [32, 33], and p2p lending [34, 35]. The various factors that provide signals such as friend network [34], price [33], previous experience [30] and online reputation [36, 37] have also been studied. In the context of sharing economy and Airbnb, researchers suggest that hosts are sending signals of listing quality or seller's trustworthiness to users with profile picture, superhost status, ID verification, and self disclosure, etc [38, 39, 40].

\section{Conceptual Framework}

Airbnb provides a variety of information about listings, including photos of the house, rooms, beds, and amenities, etc. On the contrary, there is a lack of host personal information except for profile pictures and selfintroduction. In accordance with prior literature that people rely on trustworthiness of sellers when under information scarcity, disclosing seller's face might help a buyer to build perceived trustworthiness. Consequently, we assumed that displaying the seller's face in a profile picture has a positive impact on a consumer's purchasing decision. In the context of Airbnb, we used occupancy rate as a proxy for purchase, as literature on hospitality industry widely adopted this metric to capture sales or performance, either for traditional hotels [41, 42] or new types of sharing accommodations [43, 44]. Thus, in regards to the relationship between showing face on a profile picture and the occupancy rate for Airbnb software platform, we hypothesize the following.

Hypothesis 1 The existence of face in host profile picture has a positive effect on occupancy rate.

Following with Section 2.2 group profile pictures might be perceived as a sign of sociability. Therefore, we assumed that having group type photo has positive impact on sales by increasing sellers perceived trustworthiness, hence the following hypothesis.

Hypothesis 2 The number of faces in the host profile picture has a positive impact on the occupancy rate.

Since sharing-economy, especially in the context of accommodation industry, is based on trust between the parties involved in the interaction on the platform, we explored whether the impact of number of faces on profile pictures and having a group profile picture is amplified for listings in areas with higher crime rates. In order to reduce the negative effect of less security in the area, the sellers might be taking the extra effort to post profile pictures to ignite perceived trustworthiness or the guests might be looking for extra clues to reduce their concerns. To test the validity of our assumption, we examined the moderation effect of crime rate on the relationship between profile picture and sales.

Hypothesis 3 The effect of the number of faces in the host profile picture is stronger in an area with a higher crime rate.

\section{Data and Method}

\subsection{Data Collection}

We downloaded the data set containing the Airbnb listings in the US from the Inside Airbnb website (http://insideairbnb.com). Our dataset consists of all listings available in the US from 2015 to 2021. The dataset includes 14,779 hosts, 25,811 listings, and 65,766 objects. For each listing, we recorded all attributes available from listings [45].

Next, we downloaded annual crime data from FBI Uniform Crime Reporting (UCR) program website (https: / / www.fbi.gov/services/cjis/ ucr). The dataset includes annual crime report data for each zip code. We took the sum of the violent crimes including total manslaughter, rape, arson, robbery, assault, and theft as the number of crimes. In addition, we used the maximum of number of crimes from 2015 to 2018 for each zip code to exclude the omitted year.

We divided Airbnb listing attributes into three groups (1) Listing attributes: occupancy rate, price, room type, property type, review score rating, number of rooms, etc., (3) Host attributes: host period, host identity verified, host total listings count (3) al Attributes: Crime rate, Zip code.

To measure the actual effect of the host's profile picture, we conducted preprocessing including removing the outlier listings. During the process, listings where no reviews have been written for the recent 90 days, or when all dates are occupied were removed. In the latter case, this is because inactive accommodations are sometimes marked as fully booked. In addition, Inside Airbnb has recorded how much reservation is available for each accommodation until the next 30 days based on the scrap date with the name of 'reservation 30'. We calculated the occupancy rate by subtracting the available date from 30 and dividing it by 30 . 


\subsection{Face Recognition}

We counted the number of faces in the host profile picture with DSFD (Dual Shot Face Detector), a deep learning-based face detection model. DSFD model showed the state-of-the-art performance with average precision of 0.991 in FDDB (Face Detection Dataset and Benchmark) which includes difficult pose angles, out-of-focus faces, and low resolution [46]. As grouptype profile pictures in Airbnb include low resolution and active pose subjects, we considered DSFD was the most appropriate model for this study. Accordingly, we counted faces in 14,735 profile pictures with the DSFD model, excluding the hosts who don't have profile pictures.

\subsection{Data Description}

We conduct an analysis of a total of 14,755 hosts, excluding 44 hosts that did not have profile photos, among the 14,799 hosts that existed from 2015 to 2021. The number of faces in the profile picture ranged from 0 to 21 (Figure 1). Profile photos with a single face were the most common with 8,375 and the number of group-type photos was 4,520 , accounting for $30.6 \%$ of the total.

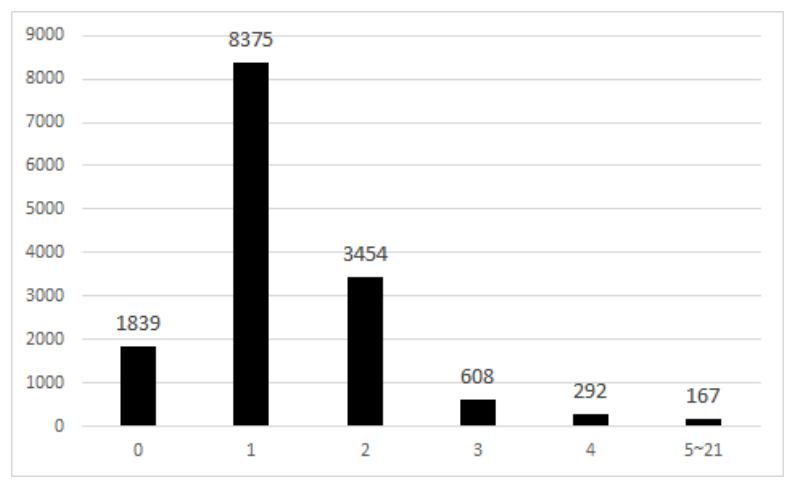

Figure 1. Distribution of the number of faces in profile photo

In the al aspect, there are 25,811 listings in 402 areas. 13,715 listings in 199 zip code areas were low-crime areas with less than 10 crimes a year which occupies $53 \%$ of all listings. On the contrary, 4,002 listings in 19 zip code had more than 1,000 crimes a year ((Figure 2). This is because both crimes and listings are concentrated in populated zip-code areas.

The occupancy rate ranged from once a month $(0.33)$ to fully booked except for one day $(0.967)$, this result came out because 0 or 1 was considered an inactive listing as described in chapter 4.1. The price per night of listing ranged from $\$ 10$ to $\$ 10,249$ with a median price of $\$ 210(\mathrm{M}=\$ 303.827, \mathrm{SD}=\$ 516.392)$. There

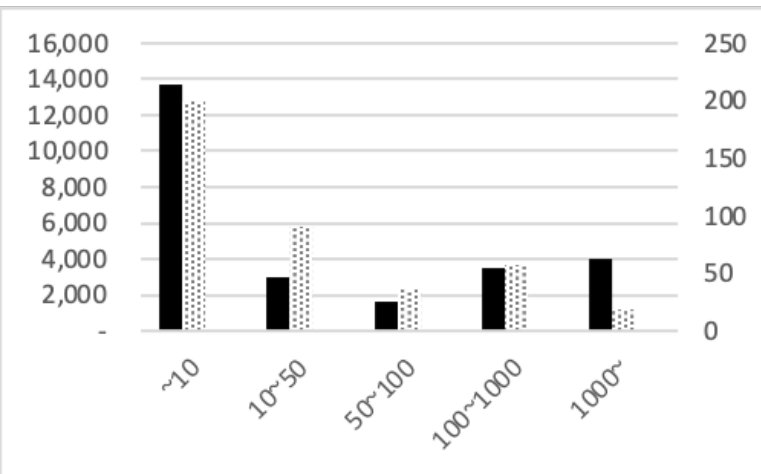

Figure 2. Distribution of the number of violent crimes by listings(black) and zip code(dotted)

are 32 property types in Airbnb. To distinguish sharing economy-oriented accommodates from traditional hotels, we classified hostel, boutique hotel, hotel, resort, aparthotel, condominium as hotel-type property. These hotel-type listings occupied $10.5 \%$ of total listings. Descriptive statistics for all predictors can be found in Table 1 and Table 2 .

Table 1. Explanation of Specific Variables

\begin{tabular}{|c|c|c|}
\hline Variable & Attribute & Description \\
\hline occupancy rate & Listing & (30-available) / 30 \\
\hline \# face & Host & Number of faces in picture \\
\hline face exist & Host & 1 if face exist in picture \\
\hline superhost & Host & 1 if host is superhost \\
\hline verified & Host & 1 if host identity verified \\
\hline host period & Host & $\begin{array}{l}\text { Months of operation for list- } \\
\text { ing }\end{array}$ \\
\hline total price & Listing & Price + cleaning fee \\
\hline instant book & Listing & $\begin{array}{l}1 \text { if accommodation do not } \\
\text { require host's permission }\end{array}$ \\
\hline amenities cnt & Listing & Number of amenities \\
\hline room type & Listing & $\begin{array}{l}\text { Whether room is \{entire } \\
\text { home, private/shared room }\end{array}$ \\
\hline property type & Listing & $\begin{array}{l}\text { Whether property is \{resort, } \\
\text { house, hotel, etc. }\end{array}$ \\
\hline bathrooms & Listing & Number of bathrooms \\
\hline bedrooms & Listing & Number of bedrooms \\
\hline beds & Listing & Number of beds \\
\hline accommodate & Listing & Number of accommodates \\
\hline rating & Listing & Mean of review rating \\
\hline min nights & Listing & Min length of stay \\
\hline review mth & Listing & $\begin{array}{l}\text { Number of reviews per } \\
\text { month }\end{array}$ \\
\hline crime $\max$ & Geog & $\begin{array}{l}\text { Max number of crimes dur- } \\
\text { ing } 2015-18 \text { bv zip code }\end{array}$ \\
\hline zipcode & Geog & Zip-code of listing location \\
\hline
\end{tabular}

\section{Results}

We created three random effect models. Given that the independent variable does not change over time, we chose a random effect model instead of a fixed effect model. 
Table 2. Descriptive statistics for categorical variables

\begin{tabular}{|c|c|c|c|}
\hline Variable & Group & $\mathrm{N}$ & $\%$ \\
\hline \multirow[t]{2}{*}{ Verified } & Yes & 29,744 & 45.23 \\
\hline & No & 36,022 & 54.77 \\
\hline \multirow[t]{2}{*}{ Superhost } & Yes & 28,468 & 43.29 \\
\hline & No & 37,298 & 56.71 \\
\hline \multirow{2}{*}{ Instant book } & Yes & 33,784 & 51.38 \\
\hline & No & 37,978 & 48.62 \\
\hline \multirow[t]{2}{*}{ Property type } & Hotel & 6,906 & 10.50 \\
\hline & Non-hotel & 58,860 & 89.50 \\
\hline \multirow{2}{*}{ Room type } & Entire home & 6,906 & 10.50 \\
\hline & Private/Share & 58,860 & 89.50 \\
\hline
\end{tabular}

Model (1) describes the correlation between the existence of face in profile pictures and the occupancy rate. Model (2) estimates the effect of number of faces in profile pictures on occupancy rate. As an extension of Model (2), Model (3) aims to catch the moderation effect of the number of crimes. The result of each model is displayed in Table 3

To test for the effect of face existence in a profile picture, we created variables named 'face exist' which is 1 if there is a face in the host's profile picture. According to the Model (1), Hypothesis 1 was highly supported. As shown in Table 3 face existence is statistically significant and positively related to occupancy rate with a coefficient of 0.0274 .

Next, we conducted analyses on the Model (2) to test the effect of the number of faces in profile pictures on the occupancy rate. By finding a statistically significant positive effect of the number of faces on occupancy rate with a coefficient of 0.006 , we can conclude that Hypothesis 2 was supported. Moreover, we captured the negative effect of the number of crimes. The variable 'crime max', which is the number of violent crimes committed in a zip code area where listings are located, had a statistically significant negative effect on the occupancy rate of listings with a coefficient of $-1.78 e^{-6}$.

The outcome of Model (3) shows a similar pattern. The number of faces has a positive significant effect on the occupancy rate with a coefficient of 0.00558 . And number of crimes indicates a statistically significant negative effect with a coefficient of $-3.29 e^{-6}$. On the contrary, the interaction term of '\# face' and 'crime max' has a positive effect on the occupancy rate with a coefficient of $1.60 e^{-6}$. In short, we found the effect of '\# face' is positively moderated by 'crime max'. This finding supports Hypothesis 3, which states that the effect of group-type profile pictures is stronger in high crime areas.
Table 3. Regression results

\begin{tabular}{|c|c|c|c|}
\hline VARIABLES & $\begin{array}{l}\text { Model (1) } \\
\text { face exist }\end{array}$ & $\begin{array}{l}\text { Model (2) } \\
\text { \#face }\end{array}$ & $\begin{array}{l}\text { Model (3) } \\
\text { interaction }\end{array}$ \\
\hline face exist & $\begin{array}{c}0.0274 * * * \\
(0.00312)\end{array}$ & & \\
\hline \# face & & $\begin{array}{c}0.00600 * * * \\
(0.000828)\end{array}$ & $\begin{array}{c}0.00558 * * * \\
(0.000846)\end{array}$ \\
\hline \# face* crime & & & $\begin{array}{l}1.60 \mathrm{e}-06^{* *} \\
(6.58 \mathrm{e}-07)\end{array}$ \\
\hline crime max & & $\begin{array}{c}-1.78 \mathrm{e}-06 * * * \\
(6.32 \mathrm{e}-07)\end{array}$ & $\begin{array}{c}-3.29 \mathrm{e}-06 * * * * \\
(8.86 \mathrm{e}-07)\end{array}$ \\
\hline total price & $\begin{array}{c}4.49 \mathrm{e}-07 \\
(2.51 \mathrm{e}-06)\end{array}$ & $\begin{array}{c}7.45 \mathrm{e}-08 \\
(2.51 \mathrm{e}-06)\end{array}$ & $\begin{array}{c}5.07 \mathrm{e}-08 \\
(2.51 \mathrm{e}-06)\end{array}$ \\
\hline accommodates & $\begin{array}{c}-0.00687 * * * \\
(0.000935)\end{array}$ & $\begin{array}{c}-0.00705^{* * *} * \\
(0.000935)\end{array}$ & $\begin{array}{c}-0.00707 * * * * \\
(0.000935)\end{array}$ \\
\hline amenities cnt & $\begin{array}{c}-0.00242 * * * \\
(0.000131)\end{array}$ & $\begin{array}{c}-0.00245^{* * *} * \\
(0.000131)\end{array}$ & $\begin{array}{c}-0.00244 * * * * \\
(0.000131)\end{array}$ \\
\hline bathrooms & $\begin{array}{c}0.00145 \\
(0.00218)\end{array}$ & $\begin{array}{l}0.000874 \\
(0.00218)\end{array}$ & $\begin{array}{l}0.000982 \\
(0.00218)\end{array}$ \\
\hline bedrooms & $\begin{array}{c}0.00476^{* *} \\
(0.00203)\end{array}$ & $\begin{array}{c}0.00542 * * * \\
(0.00203)\end{array}$ & $\begin{array}{c}0.00530^{* * * *} \\
(0.00203)\end{array}$ \\
\hline beds & $\begin{array}{l}0.000822 \\
(0.00115)\end{array}$ & $\begin{array}{l}0.000679 \\
(0.00115)\end{array}$ & $\begin{array}{l}0.000689 \\
(0.00115)\end{array}$ \\
\hline verified & $\begin{array}{c}0.0623 * * * \\
(0.00264)\end{array}$ & $\begin{array}{c}0.0644 * * * \\
(0.00264)\end{array}$ & $\begin{array}{l}0.0642 * * * \\
(0.00264)\end{array}$ \\
\hline \# reviews & $\begin{array}{c}-0.000197 * * * \\
(2.29 \mathrm{e}-05)\end{array}$ & $\begin{array}{c}-0.000198 * * * \\
(2.29 \mathrm{e}-05)\end{array}$ & $\begin{array}{c}-0.000199^{* * * *} \\
(2.29 \mathrm{e}-05)\end{array}$ \\
\hline rating & $\begin{array}{c}0.00116^{* * * *} \\
(0.000181)\end{array}$ & $\begin{array}{l}0.00121 * * * \\
(0.000180)\end{array}$ & $\begin{array}{c}0.00121 * * * \\
(0.000180)\end{array}$ \\
\hline superhost & $\begin{array}{l}-0.00110 \\
(0.00271)\end{array}$ & $\begin{array}{c}-0.000350 \\
(0.00271)\end{array}$ & $\begin{array}{c}-0.000140 \\
(0.00271)\end{array}$ \\
\hline host period & $\begin{array}{l}-2.25 \mathrm{e}-06 \\
(1.70 \mathrm{e}-06)\end{array}$ & $\begin{array}{l}-1.72 \mathrm{e}-06 \\
(1.70 \mathrm{e}-06)\end{array}$ & $\begin{array}{l}-1.86 \mathrm{e}-06 \\
(1.70 \mathrm{e}-06)\end{array}$ \\
\hline \# listings & $\begin{array}{c}-3.85 \mathrm{e}-05^{* * * *} \\
(5.62 \mathrm{e}-06)\end{array}$ & $\begin{array}{c}-4.94 \mathrm{e}-05^{* * * *} \\
(5.51 \mathrm{e}-06)\end{array}$ & $\begin{array}{c}-4.86 \mathrm{e}-05^{* * * *} \\
(5.52 \mathrm{e}-06)\end{array}$ \\
\hline instant book & $\begin{array}{c}-0.00532 * * \\
(0.00250)\end{array}$ & $\begin{array}{c}-0.00722 * * * \\
(0.00249)\end{array}$ & $\begin{array}{c}-0.00704 * * * \\
(0.00249)\end{array}$ \\
\hline zip code & $\begin{array}{c}4.04 \mathrm{e}-08 \\
(3.67 \mathrm{e}-08)\end{array}$ & $\begin{array}{c}4.20 \mathrm{e}-08 \\
(3.68 \mathrm{e}-08)\end{array}$ & $\begin{array}{l}4.06 \mathrm{e}-08 \\
(3.68 \mathrm{e}-08)\end{array}$ \\
\hline min nights & $\begin{array}{c}0.000239 \\
(0.000176)\end{array}$ & $\begin{array}{c}0.000217 \\
(0.000176)\end{array}$ & $\begin{array}{c}0.000211 \\
(0.000176)\end{array}$ \\
\hline review mth & $\begin{array}{l}0.0211 * * * \\
(0.000754)\end{array}$ & $\begin{array}{l}0.0215^{* * * *} \\
(0.000752)\end{array}$ & $\begin{array}{l}0.0214 * * * \\
(0.000752)\end{array}$ \\
\hline Constant & $\begin{array}{c}0.316^{* * * *} \\
(0.0172)\end{array}$ & $\begin{array}{c}0.326 * * * \\
(0.0172)\end{array}$ & $\begin{array}{c}0.327 * * * \\
(0.0172)\end{array}$ \\
\hline $\begin{array}{l}\text { Observations } \\
\text { \# listing id }\end{array}$ & $\begin{array}{l}65,766 \\
25,811\end{array}$ & $\begin{array}{l}65,766 \\
25,811\end{array}$ & $\begin{array}{l}65,766 \\
25,811\end{array}$ \\
\hline
\end{tabular}

\section{Robustness Check}

To clearly identify the effect of the number of faces in host profile picture on occupancy rate and the moderation effect of crime, we did data subsampling by splitting our dataset based on two criteria: crime rate and space sharing.

In this study, we assumed that people may be concerned about sharing a space with strangers through a software platforms. Accordingly, the signal on safety can have a positive impact on the occupancy rate in Airbnb. However, one potential concern with our analysis is that Airbnb also has a form of accommodation that does not share space with hosts. So, we categorized listings into 'with host' and 'without host' in terms of space sharing. We assumed that visitors are not sharing the place with hosts in listings whose room-type is 'Entire 
home/apt' or whose property-type is 'hotel', 'boutique hotel', 'resort', etc. On the other hand, listing whose room-type is 'private room' or 'shared room' are classified as 'with host'.

We also extracted listings at both ends of the crime distribution. Areas where violent crime occurs less than once a month are assumed to be 'low-crime rate areas'. On the contrary, listings located in the area where violent crime occurs more than once a week are assumed to be in 'high-crime rate areas'. As a result, we split our dataset into four samples: (1) high-crime rate \& with host, (2) low-crime rate \& without host (3) high crime rate \& without host, (4) low-crime rate $\&$ without host. The results are described in Table 4.

We found that the impact of variable '\# face' is the largest on the sample (1). Listings that share the space with host and located in low crime rate area receive the second largest impact from the variable '\# face'. The number of faces in host profile photos has the third largest impact on not-sharing type listing in high crime rate area, and shows the lowest impact on the listings that are located in areas with low crime rates and do not share space with hosts. As indicated above, our results are robust after we divide our dataset according to two criteria.

\section{Conclusion and Discussion}

This study utilizes panel datasets extracted from Airbnb's data every month from 2015 to 2021 . However, the existing picture is deleted from the Airbnb server if a host changed their profile picture. Therefore, we cannot track the history of the host changing the picture. As we cannot estimate the change of independent variable, some of the models including the fixed effect model and event-based studies are not applicable. To overcome these limitations, we will continue to track changes in the host's profile picture for the purpose of applying event-based methodology such as 'difference in difference' model.

In addition, this form of seller uncertainty may vary depending on the gender, race, age, etc. of tourists. For example, young Asian women are believed to have a higher sensitivity to crime than older white men, so signal effects on safety may be more important. As a consequence, experimental studies on whether these buyer characteristics regulate signal effects on safety are also considered as follow-up studies.

Recently growing online-based platforms, including sharing economy platforms, go beyond connecting sellers and buyers online and serve as intermediaries for offline meetings. While the economic importance of these online-to-offline $(\mathrm{O} 2 \mathrm{O})$ platforms is increasing, the cur- rent literature only consider the seller uncertainty in the scope of the traditional online market. The traditional concept of seller uncertainty focuses on whether sellers are reliable when the consumer predicts the quality of a product. However, in services where sellers and buyers meet directly, such as sharing economy, the role of sellers goes beyond just selling goods to become part of the service. Despite the uncertainty of sellers in the new type of online market that can undoubtedly pose additional risks to buyers, such as safety, research in this domain has been insufficient. We hope this study sheds light on future research on seller uncertainty by finding its additional roles and risks in emerging markets.

In addition, we believe this research helps platform service providers (Airbnb hosts in this case) by showing the importance of profile pictures. At the same time, we also demonstrated the relevance of demand for tools that can reduce seller uncertainty. Based on these results, we suggest platform owners develop additional venues to give users sufficient information about sellers. We also believe that this study will be a guide for policymakers in high crime areas to attract tourists.

\section{References}

[1] R. Botsman and R. Rogers, "What's mine is yours," The rise of collaborative consumption, 2010.

[2] A. Dimoka, Y. Hong, and P. A. Pavlou, "On product uncertainty in online markets: Theory and evidence," MIS quarterly, pp. 395-426, 2012.

[3] C. Dellarocas, "Reputation mechanism design in online trading environments with pure moral hazard," Information systems research, vol. 16, no. 2, pp. 209-230, 2005.

[4] A. Ghose, "Internet exchanges for used goods: An empirical analysis of trade patterns and adverse selection," Mis Quarterly, pp. 263-291, 2009.

[5] S. S. Kirsten Grind, "Shooting, sex crime and theft: Airbnb takes halting steps to protect its users," 2019.

[6] K. Conger, "Uber says 3,045 sexual assaults were reported in u.s. rides last year," 2019.

[7] E. Ert, A. Fleischer, and N. Magen, "Trust and reputation in the sharing economy: The role of personal photos in airbnb," Tourism management, vol. 55, pp. 62-73, 2016.

[8] B. Jaeger, W. W. Sleegers, A. M. Evans, M. Stel, and I. van Beest, "The effects of facial attractiveness and trustworthiness in online peer-to-peer markets," Journal of economic psychology, vol. 75, p. 102125, 2019.

[9] D. Guttentag, "Airbnb: disruptive innovation and the rise of an informal tourism accommodation sector," Current issues in Tourism, vol. 18, no. 12, pp. 1192-1217, 2015.

[10] J. Duarte, S. Siegel, and L. Young, "Trust and credit: The role of appearance in peer-to-peer lending," The Review of Financial Studies, vol. 25, no. 8, pp. 2455-2484, 2012.

[11] B. J. Fogg and H. Tseng, "The elements of computer credibility," in Proceedings of the SIGCHI conference on Human Factors in Computing Systems, pp. 80-87, 1999. 
Table 4. Robustness Check

(1) (2) (3) (4)

VARIABLES high crime \& host low crime \& host high crime \& w/o host low crime \& w/o hos

\begin{tabular}{|c|c|c|c|c|}
\hline \# face & $\begin{array}{c}0.0128 * * * \\
(0.00495)\end{array}$ & $\begin{array}{c}0.0126 * * * \\
(0.00448)\end{array}$ & $\begin{array}{c}0.0116 * * * \\
(0.00219)\end{array}$ & $\begin{array}{c}0.00515 * * * \\
(0.000956)\end{array}$ \\
\hline \multirow[t]{2}{*}{ total price } & $1.75 \mathrm{e}-05$ & $6.06 \mathrm{e}-05$ & $-1.48 \mathrm{e}-05 * * *$ & $6.74 \mathrm{e}-06^{* *}$ \\
\hline & $(1.99 \mathrm{e}-05)$ & $(6.25 \mathrm{e}-05)$ & $(4.34 \mathrm{e}-06)$ & $(3.15 \mathrm{e}-06)$ \\
\hline \multirow[t]{2}{*}{ rating } & 0.000912 & $0.00240 * * *$ & $0.00190 * * *$ & $0.000842 * * *$ \\
\hline & $(0.000630)$ & $(0.000559)$ & $(0.000316)$ & $(0.000281)$ \\
\hline \multirow[t]{2}{*}{ review mth } & $0.0211 * * *$ & $0.0263 * * *$ & $0.0220 * * *$ & $0.0130 * * *$ \\
\hline & $(0.00207)$ & $(0.00209)$ & $(0.00121)$ & $(0.000970)$ \\
\hline \multirow[t]{2}{*}{ host period } & $1.37 \mathrm{e}-05^{* *}$ & $-6.40 e-06$ & $-1.40 \mathrm{e}-05^{*} * *$ & $-4.71 \mathrm{e}-06 * *$ \\
\hline & $(5.62 \mathrm{e}-06)$ & $(4.74 \mathrm{e}-06)$ & $(2.93 e-06)$ & $(2.37 \mathrm{e}-06)$ \\
\hline \multirow[t]{2}{*}{ superhost } & -0.00158 & $-0.0173 * *$ & -0.00495 & 0.00560 \\
\hline & $(0.00968)$ & $(0.00866)$ & $(0.00504)$ & $(0.00403)$ \\
\hline \multirow[t]{2}{*}{ \# listings } & $-0.00121 * * *$ & $-8.19 \mathrm{e}-05$ & $-1.43 e-05$ & $-5.36 \mathrm{e}-05 * * *$ \\
\hline & $(0.000323)$ & $(0.000262)$ & $(1.14 \mathrm{e}-05)$ & $(6.71 \mathrm{e}-06)$ \\
\hline \multirow[t]{2}{*}{ verified } & $0.0553 * * *$ & $0.0709 * * *$ & $0.0538 * * *$ & $0.0740 * * *$ \\
\hline & $(0.00911)$ & $(0.00767)$ & $(0.00501)$ & $(0.00387)$ \\
\hline \multirow[t]{2}{*}{ accommodate } & 0.00291 & -0.00379 & $-0.00763 * * *$ & $-0.00637 * * *$ \\
\hline & $(0.00486)$ & $(0.00458)$ & $(0.00158)$ & $(0.00131)$ \\
\hline \multirow[t]{2}{*}{ amenities cnt } & $-0.00210 * * *$ & $-0.00475 * * *$ & $-0.00143 * * *$ & $-0.00294 * * *$ \\
\hline & $(0.000481)$ & $(0.000444)$ & $(0.000241)$ & $(0.000187)$ \\
\hline \multirow{2}{*}{ bathrooms } & 0.00449 & $0.0179 * *$ & 0.00483 & -0.00463 \\
\hline & $(0.00799)$ & $(0.00842)$ & $(0.00351)$ & $(0.00343)$ \\
\hline \multirow[t]{2}{*}{ bedrooms } & 0.00170 & 0.00865 & $0.0102 * * *$ & 0.00218 \\
\hline & $(0.0145)$ & $(0.0144)$ & $(0.00355)$ & $(0.00281)$ \\
\hline \multirow[t]{2}{*}{ beds } & -0.0110 & -0.00356 & 0.00315 & 0.00104 \\
\hline & $(0.00720)$ & $(0.00749)$ & $(0.00234)$ & $(0.00144)$ \\
\hline \multirow[t]{2}{*}{ Constant } & $0.242 * * *$ & $0.162 * * *$ & $0.218 * * *$ & $0.392 * * *$ \\
\hline & $(0.0608)$ & $(0.0539)$ & $(0.0298)$ & $(0.0262)$ \\
\hline Observations & 4,951 & 7,559 & 17,172 & 30,667 \\
\hline \# listing id & 2,191 & 2,895 & 6,958 & 11,764 \\
\hline
\end{tabular}

[12] O. B. Büttner and A. S. Göritz, "Perceived trustworthiness of online shops," Journal of Consumer Behaviour: An International Research Review, vol. 7, no. 1, pp. 3550, 2008

[13] L. Peng, G. Cui, Y. Chung, and W. Zheng, "The faces of success: Beauty and ugliness premiums in e-commerce platforms," Journal of Marketing, vol. 84, no. 4, pp. 6785,2020

[14] P. Broeder and E. Remers, "Eye contact and trust online: the effect of profile pictures on airbnb booking," in 2018 IEEE 12th International Conference on Application of Information and Communication Technologies (AICT), pp. 1-4, IEEE, 2018.

[15] C. Deng and T. R. Ravichandran, "To smile or not? the effect of facial expression on service demand in sharing economy platforms," 2020.

[16] J. C. McCroskey and T. A. Jenson, "Image of mass media news sources," Journal of Broadcasting \& Electronic
Media, vol. 19, no. 2, pp. 169-180, 1975.

[17] E. K. Simpson and R. C. Kahler, "A scale for source credibility; validated in the selling context," Journal of Personal Selling \& Sales Management, vol. 1, no. 1, pp. 17$25,1981$.

[18] G. W. Wynn, "The effects of a salespersons' credibility on other salespersons and sales managers," in Proceedings of the 1987 Academy of Marketing Science (AMS) Annual Conference, pp. 353-358, Springer, 2015.

[19] S. Banerjee, S. Bhattacharyya, and I. Bose, "Whose online reviews to trust? understanding reviewer trustworthiness and its impact on business," Decision Support Systems, vol. 96, pp. 17-26, 2017.

[20] J. B. Walther, "Selective self-presentation in computermediated communication: Hyperpersonal dimensions of technology, language, and cognition," Computers in $\mathrm{Hu}$ man Behavior, vol. 23, no. 5, pp. 2538-2557, 2007. 
[21] J. B. Walther, B. Van Der Heide, S.-Y. Kim, D. Westerman, and S. T. Tong, "The role of friends' appearance and behavior on evaluations of individuals on facebook: Are we known by the company we keep?," Human communication research, vol. 34, no. 1, pp. 28-49, 2008.

[22] C. L. Toma, "Counting on friends: Cues to perceived trustworthiness in facebook profiles," in Eighth International AAAI Conference on Weblogs and Social Media, 2014.

[23] S. Hong, E. Tandoc Jr, E. A. Kim, B. Kim, and K. Wise, "The real you? the role of visual cues and comment congruence in perceptions of social attractiveness from facebook profiles," Cyberpsychology, Behavior, and Social Networking, vol. 15, no. 7, pp. 339-344, 2012.

[24] S. T. Tong, B. Van Der Heide, L. Langwell, and J. B. Walther, "Too much of a good thing? the relationship between number of friends and interpersonal impressions on facebook," Journal of computer-mediated communication, vol. 13, no. 3, pp. 531-549, 2008.

[25] N. C. Krämer, M. Feurstein, J. P. Kluck, Y. Meier, M. Rother, and S. Winter, "Beware of selfies: the impact of photo type on impression formation based on social networking profiles," Frontiers in psychology, vol. 8, p. 188, 2017.

[26] M. Milyavskaya, J. Reoch, R. F. Koestner, and G. F. Losier, "Seeking social connectedness: Interdependent self-construal and impression formation using photographic cues of social connectedness," The Journal of social psychology, vol. 150, no. 6, pp. 689-702, 2010.

[27] B. L. Connelly, S. T. Certo, R. D. Ireland, and C. R. Reutzel, "Signaling theory: A review and assessment," Journal of management, vol. 37, no. 1, pp. 39-67, 2011.

[28] M. Spence, "Job market signalling": The quarterly journal of economics"," 1973.

[29] A. Kirmani and A. R. Rao, "No pain, no gain: A critical review of the literature on signaling unobservable product quality," Journal of marketing, vol. 64, no. 2, pp. 6679, 2000 .

[30] C. Courtney, S. Dutta, and Y. Li, "Resolving information asymmetry: Signaling, endorsement, and crowdfunding success," Entrepreneurship Theory and Practice, vol. 41, no. 2, pp. 265-290, 2017.

[31] N. Wang, H. Liang, Y. Xue, and S. Ge, "Mitigating information asymmetry to achieve crowdfunding success: Signaling and online communication," Journal of the Association for Information Systems, vol. 22, no. 3, p. 4, 2021.

[32] T. Mavlanova, R. Benbunan-Fich, and M. Koufaris, "Signaling theory and information asymmetry in online commerce," Information \& Management, vol. 49, no. 5, pp. 240-247, 2012.

[33] D. Mitra and S. Fay, "Managing service expectations in online markets: A signaling theory of e-tailer pricing and empirical tests," Journal of retailing, vol. 86, no. 2, pp. 184-199, 2010.

[34] M. Lin, N. R. Prabhala, and S. Viswanathan, "Judging borrowers by the company they keep: Friendship networks and information asymmetry in online peer-to-peer lending," Management Science, vol. 59, no. 1, pp. 17-35, 2013.

[35] B. C. Collier and R. Hampshire, "Sending mixed signals: Multilevel reputation effects in peer-to-peer lending markets," in Proceedings of the 2010 ACM conference on Computer supported cooperative work, pp. 197-206, 2010.
[36] N. Amblee and T. Bui, "Harnessing the influence of social proof in online shopping: The effect of electronic word of mouth on sales of digital microproducts," International journal of electronic commerce, vol. 16, no. 2 , pp. 91-114, 2011.

[37] J. Li, J. Tang, L. Jiang, D. C. Yen, and X. Liu, "Economic success of physicians in the online consultation market: a signaling theory perspective," International Journal of Electronic Commerce, vol. 23, no. 2, pp. 244-271, 2019.

[38] T. Teubner, F. Hawlitschek, and D. Dann, "Price determinants on airbnb: How reputation pays off in the sharing economy," Journal of Self-Governance and Management Economics, vol. 5, no. 4, pp. 53-80, 2017.

[39] X. Ma, J. T. Hancock, K. Lim Mingjie, and M. Naaman, "Self-disclosure and perceived trustworthiness of airbnb host profiles," in Proceedings of the 2017 ACM conference on computer supported cooperative work and social computing, pp. 2397-2409, 2017.

[40] K. Xie and Z. Mao, "The impacts of quality and quantity attributes of airbnb hosts on listing performance," International Journal of Contemporary Hospitality Management, 2017.

[41] G. Viglia, R. Minazzi, and D. Buhalis, "The influence of e-word-of-mouth on hotel occupancy rate," International Journal of Contemporary Hospitality Management, 2016.

[42] P. De Pelsmacker, S. Van Tilburg, and C. Holthof, "Digital marketing strategies, online reviews and hotel performance," International Journal of Hospitality Management, vol. 72, pp. 47-55, 2018.

[43] G. Zervas, D. Proserpio, and J. W. Byers, "The rise of the sharing economy: Estimating the impact of airbnb on the hotel industry," Journal of marketing research, vol. 54, no. 5, pp. 687-705, 2017.

[44] C. Y. Heo, I. Blal, and M. Choi, "What is happening in paris? airbnb, hotels, and the parisian market: A case study," Tourism Management, vol. 70, pp. 78-88, 2019.

[45] A. Sundararajan, "Peer-to-peer businesses and the sharing (collaborative) economy: Overview, economic effects and regulatory issues," Written testimony for the hearing titled The Power of Connection: Peer to Peer Businesses, pp. 1-7, 2014.

[46] J. Li, Y. Wang, C. Wang, Y. Tai, J. Qian, J. Yang, C. Wang, J. Li, and F. Huang, "Dsfd: dual shot face detector," in Proceedings of the IEEE/CVF Conference on Computer Vision and Pattern Recognition, pp. 50605069, 2019. 